\title{
Patricia Pisters
}

\section{Lessen van Hitchcock. Een inleiding in de mediatheorie}

Amsterdam (Amsterdam University Press) 2002, 328 p., € 27,50, ISBN 905356505 I

Het was er nog niet, een in het Nederlands geschreven of vertaalde inleiding over mediatheorieën. Maar Patricia Pisters, werkzaam als universitair hoofddocent bij de leerstoelgroep Film- en Televisiewetenschappen (UvA), heeft met een kloek boek deze leemte gevuld. Of gaat het om een semi-leemte? Immers aan Engelstalige inleidingen in de film- en televisietheorie is geen gebrek. Toch lijkt het ontbreken van een Nederlandse versie niet de voornaamste reden voor deze publicatie. Die ligt vooral in twee andere zaken: met 'media' worden niet alleen film en televisie bedoeld, maar de in dit boek beschreven theorieën omvatten ook de nieuwe media. Bovendien heeft Pisters voor een specifieke invalshoek gekozen, namelijk het bespreken van theorieën waarbij vooral de films en tv-series van Hitchcock als illustratiemateriaal fungeren.

De opzet is zowel historisch als anachronistisch. De auteur bekijkt theorieën, ontwikkeld vanaf de jaren vijftig, ook op hun verdiensten voor recentere media en sommige films uit het verleden toetst zij op hun beurt op hun postmoderniteit. De auteur omschrijft mediatheorieën als denkmodellen waarmee aspecten van verschillende media verklaard en begrepen kunnen worden. Er bestaat geen theorie die dé waarheid in pacht heeft, maar het is 'een bril die bepaalde dingen scherper laat zien' (p. 17).

Pisters begint haar overzicht in de jaren vijftig, omdat toen voor het eerst gepoogd werd om de geesteswetenschappen - en dan vooral taal- en literatuurstudies - een wetenschappelijke basis en status te geven. Mediastudies (in eerste instantie filmstudies) ontleenden wat hun theorievorming betreft nu eenmaal veel aan literatuurstudies. Het structuralisme was een van de eerste aanzetten tot de ontwikkeling van een totaaltheorie en is ming sprak uitsluitend van 'teksten' en han-

teerde daarmee een media-overschrijdende benadering. Het zoeken naar algemene patronen en structuren in het netwerk van tekens waaruit een tekst is opgebouwd, vervangt de in de jaren vijftig ontwikkelde auteursbenadering. Terwijl hierin de biografie van de regisseur nog als een belangrijk uitgangspunt fungeert om specifieke stijlpatronen in een filmoeuvre te ontdekken (en te verklaren), gaat het in de structuralistisch georiënteerde theorieën - zoals narratologie, semiologie en psychoanalytische filmtheorie - vooral om algemene onderliggende onbewuste patronen. De auteurtheorie heeft weliswaar interessante aanzetten gegeven tot genrestudies, maar met het 'dood verklaren' van de auteur - in de structuralistische benadering - is de academische aandacht volledig verschoven naar het niveau van de tekst zelf. Dat wil zeggen dat niet de auteur/regisseur als verantwoordelijk wordt gezien voor de betekenissen die film, televisie en nieuwe media produceren, maar de organisatie van de tekst zelf, op een onderliggend abstract niveau.

Zoals Pisters aangeeft ontwikkelt theorie zich niet in een maatschappelijk vacuüm; een uitsluitend tekst-immanente benadering kent zo haar beperkingen. In de jaren zeventig en tachtig zien we dan ook de opkomst van ideologie-kritische, feministische/gender/cyber/queerperspectieven die weer uitmondden in de studie van nationale cinema, in het amalgaam culturele studies, in de cognitieve invalshoek (waarin, we zouden het bijna vergeten, de kijker zelf centraal staat) en uiteindelijk in de postmoderne mediatheorie. Hoewel in deze benaderingen visuele aspecten veelal het uitgangspunt zijn, is vooral in het afgelopen decennium veel aan theorievorming over het geluid gedaan: in een apart hoofdstuk bespreekt Pisters deze benadering niet alleen aan de hand van Hitchcock's geluidsexperimenten, maar ook van Madonna's prachtige videoclip JUSTIFY MY 
LoVE. Terzijde zij vermeld dat de auteur zich met de publicatie van Madonna (1999, met co-auteur Hannah Bosma) ook tot een expert op het terrein van de beeldpresentaties en performances van de megaster kan rekenen. Uit deze bron wordt dan ook regelmatig geput.

Toch zijn niet alle theoretische perspectieven even helder beschreven. Zoals bijvoorbeeld in de benadering van het modernisme, dat omschreven wordt als een 'streven naar puurheid' en als een 'reactie op het realisme'. Beide kwalificaties mogen waar zijn, maar wat verduidelijken ze? Hoe ziet 'puurheid' eruit in film, kunst, muziek en literatuur? Want waarom noemen we Godard (die vreemd genoeg niet als voorbeeld wordt aangehaald), Mondriaan, Schönberg en Joyce modernisten? Omdat zij in hun werk niet in de eerste plaats naar een wereld buiten de tekst verwijzen (zoals het realisme deed), maar juist de karakteristieke aspecten van het medium zelf op de voorgrond plaatsen. Je wordt als kijker niet het beeld 'ingetrokken', maar juist geconfronteerd met hoe dat beeld tot stand komt of is gekomen, met het maakproces. Modernistische films verwijzen naar zichzelf, maken de kijker bewust van de montage, de camera, het geluid, et cetera en de 'verhalen' worden niet meer per definitie in een chronologische orde verteld. Als modernisme zo wordt uitgelegd, is het heel wat problematischer om Hitchcock in een modernistisch kader te plaatsen, hoewel zijn films zeker modernistische momenten kennen. Maar juist iemand die zo effectief en gecontroleerd mogelijk een verhaal probeert te vertellen, zoals Pisters zegt dat Hitchcock doet (p. 261), lijkt mij eerder van het tegendeel van modernisme te getuigen. Immers de meeste (klassieke) Hollywoodregisseurs deden dat.
Een soortgelijke kritiek heb ik op Pisters' poging om Hitchcock bij het postmodernisme in te lijven. Zeker, de postmodernistische cultuur maakt gretig gebruik van de rijke visuele bron die Hitchcock ons heeft nagelaten, maar hem postmodernistisch noemen omdat hij zich bewust was van zijn status als mediaster en omdat hij - net als Andy Warhol (!) - kunstzinnigheid paarde aan een gevoel voor commercie, doet op zijn minst geforceerd aan.

Dat het boek desondanks in de eerste plaats voor studenten een nuttig instrument kan zijn, staat buiten kijf. Pisters wil 'verschillende theoretische posities herkenbaar maken en de verschillende vragen en problemen die worden onderzocht met elkaar vergelijken en evalueren' (p. 17). Voor studenten betekent dit dat zij leren herkennen welke theoretische visie aan een artikel of boek ten grondslag ligt, dat zij op de hoogte zijn van het reeds bestaande kritische commentaar op de desbetreffende theorie en dat zij in hun essays of werkstukken weten welke theoretische invalshoek ze het beste kunnen kiezen bij een bepaalde vraagstelling. Studenten - maar zij niet alleen - hebben nogal eens de neiging om klakkeloos de meest recente theorieën te gebruiken, als zou het gaan om een modeartikel: Roland Barthes is uit, Gilles Deleuze is in. Terecht waarschuwt Pisters dan ook voor een 'opportunistisch relativisme' en pleit zij voor het creëren van een kritisch bewustzijn waarmee theorieën moeten worden benaderd. Door de doorgaans heldere manier waarop zij de theorieën uitlegt, in hun context plaatst, becommentarieert en met herkenbare voorbeelden illustreert zal het boek in de toekomst voor honderden studenten ongetwijfeld een baken zijn dat hen langs de klippen van het 'theoretisch' mijnenveld loodst. 